\title{
"Combater a ignorância é defender a liberdade": as relações entre a Associação Comercial do Rio de Janeiro e o Liceu de Artes e Ofícios no Império
}

\section{"Oppose to ignorance is defending freedom": Relations between the Commercial Association of Rio de Janeiro and the School of Arts and Crafts during the Empire}

\author{
Mônica de Souza Nunes Martins*
}

\begin{abstract}
RESUMO
O artigo apresenta os interesses da Associação Comercial do Rio de Janeiro no estímulo e patrocínio à implementação do curso comercial pelo Liceu de Artes e Ofícios do Rio de Janeiro. Analisando os aspectos que envolveram a afirmação da instrução pública ao longo do século XIX, o artigo transita por vários aspectos da sociedade e economia da segunda metade do século XIX que formavam um novo entendimento sobre a instrução pública, articulando-a aos interesses da produção de riqueza do país e, ao mesmo tempo, incentivando o ensino profissional como formador e moralizador da classe trabalhadora. Nesse sentido, o artigo discute alguns aspectos históricos que teriam contribuído para a defesa do ensino comercial, como aspecto da formação profissional dos trabalhadores do comércio, pela Associação Comercial do Rio de Janeiro no final dos oitocentos.

Palavras-chave: Associação Comercial do Rio de Janeiro. Liceu de Artes e Ofícios. Ensino Comercial. Instrução Pública. Século XIX.
\end{abstract}

* Universidade Federal Rural do Rio de Janeiro. Programa de Pós-Graduação em História. Nova Iguaçu, Rio de Janeiro, Brasil. E-mail: monic1922@gmail.com. http://orcid.org/0000-00030917-3437 


\begin{abstract}
This paper investigates the interests of the Commercial Association of Rio de Janeiro, encouraging and sponsoring the implementation of the Commercial course at the School of Arts and Crafts of Rio de Janeiro. Analyzing aspects involving the setting of public education throughout the nineteenth century, the paper moves through various aspects of society and economy in the second half of the nineteenth century which formed a new understanding of public education, in an attempt to link it to the interests of production, wealth of the country and at the same time encouraging vocational education as trainer and moralizing the working class. Therefore, the paper discusses some historical aspects that have contributed to the defense of business education, as a part of professional training of workers in trade by the Commercial Association of Rio de Janeiro in the late eighteen hundreds.

Keywords: Commercial Association of Rio de Janeiro. School of Arts and Crafts of Rio de Janeiro. Commercial Education. Public Instruction. Nineteenth century.
\end{abstract}

\title{
Preocupações com a instrução pública e o ensino profissional no Império
}

Parecia ocupar a vida política do início dos oitocentos um crescente interesse pela instrução pública no Brasil. Em 1815, vários comerciantes do Rio ofereceram ao monarca uma soma em dinheiro que deveria ser aplicada na promoção da instrução. Esse grupo designou Fernando Carneiro Leão para oferecer a D. João a subscrição para a Educação Pública (MURASSE, 2001, p. 61).

As primeiras iniciativas de investimento numa instrução pública tomaram forma no Brasil nos oitocentos. A responsabilidade em relação ao ensino, atribuída nos séculos anteriores, em grande parte, aos religiosos, tornava-se preocupação do governo imperial após a emancipação. Na Constituição de 1824, garantia-se a instrução primária e gratuita a todos os cidadãos, assim como era prevista a instalação de colégios e universidades para o ensino das Ciências, Belas Artes e Letras. A Lei de 15 de outubro de 1827 determinava a criação de estabelecimentos de ensino em todas as cidades e vilas do Império, prevendo ainda a abertura de estabelecimentos especialmente para as meninas (MATTOS, 1994, p. 243-244). Essa Lei instituía a responsabilidade dos Presidentes de Províncias na escolha dos lugares para a instalação das escolas, assim como a fiscalização, a nomeação e a suspensão de professores, cabendo a cada província organizar e fiscalizar a instrução pública dentro dos seus municípios e vilas. 
De acordo com Gondra e Schueler, "o objetivo da política de estabelecimento da instrução pública nas primeiras décadas que se seguiram à independência consistia em produzir identidades e laços de interdependência sociais, integrando os brasileiros, o povo, conjunto dos cidadãos ativos e inativos ao Estado" (GONDRA; SCHUELER, 2008, p. 29-30). A formação do "povo" era crucial para a construção da nacionalidade, instrumento fundamental às perspectivas de unidade territorial e política. No entanto, ao mesmo tempo em que se ampliava o apoio de setores ao ensino das classes trabalhadoras, o permanente conflito pelo acesso se instalava: as leis provinciais que se seguiram ao Ato Adicional de 1834 proibiam que negros frequentassem escolas públicas (VILLELA, 2012, p. 162), mesmo que fossem livres. Os debates sobre a extensão da instrução deparavam-se com a realidade dos negros estarem formalmente excluídos das políticas de instrução (GONDRA; SCHUELER, 2008, p. 33).

A construção do Império brasileiro após a independência foi marcada, no entanto, pela dupla dimensão ideológica que a instrução assumia: primeiro, porque à organização do poder correspondiam novas formas de organização do saber; segundo, porque essa nova organização espelhava o distanciamento político entre a classe dominante e os setores mais pobres da sociedade, por meio da hierarquização entre formações escolares distintas. Sobretudo após os anos 1840, o processo de centralização conduziu à reafirmação dessas distinções, com a criação de instituições de elite com o respaldo imperial.

A experiência da Academia Imperial de Belas Artes - na tentativa de associar o ensino de artes liberais e das artes mecânicas - talvez tenha sido uma das mais abrangentes tentativas de ensino das artes, numa amplitude maior do que aquela para a qual o ensino de ofícios acabou sendo orientado. A proposta de Araújo Porto Alegre em articular essas duas perspectivas, embasada no estímulo promovido pela Reforma Pedreira, caracterizou-se como o mais forte impulso à associação entre as artes, numa articulação entre o trabalho mecânico e o trabalho intelectual. As dificuldades enfrentadas ao longo do século com a instituição das escolas de artes e ofícios (SQUEFF, 2004, p. 52) aparecem com seus limites após a década de 1850, quando foi preciso criar uma organização efetiva de funcionamento e de formação na esfera do ensino profissional na Corte que fosse exemplar para as demais províncias.

Ainda na década de 1850 , foi criada a instituição que se tornou o símbolo da formação profissional no Brasil: O Liceu de Artes e Ofícios do Rio de Janeiro (LAO), em 1858. O decreto que autorizava o seu funcionamento previa uma instituição que cuidasse da educação para o trabalho, com finalidade profissionalizante. O Liceu deveria atuar na formação dos trabalhadores para a indústria, distinguindo-se da educação dispensada à formação de engenheiros, atribuição a ser desempenhada pela Escola Politécnica (CUNHA, 2000, 
p. 120). O Liceu era uma instituição privada, mas recebia fortes incentivos do governo, tanto com apoio, quanto a subvenção, especialmente valendo-se do repasse de loterias. Segundo a designação do jornal O Paiz, a principal missão do Liceu de Artes e Ofícios se constituía em disseminar "pelo povo, educação, o conhecimento do - bello -, propagar e desenvolver, pelas classes operárias, a instrucção indispensável ao exercício racional da parte artística e technica das artes, officios e industrias" (O PAIZ, 1885).

A formação do Liceu de Artes e Ofícios no Rio de Janeiro teve um papel relacionado, por um lado, à elaboração de uma nova concepção sobre a formação técnica e profissional; por outro, representou o momento de ressignificação das artes mecânicas e liberais, com ênfase no ensino destinado ao "progresso da indústria". Essa distinção marcou toda a nova concepção também sobre as artes, o trabalho e a formação profissional no Brasil. Ao Liceu couberam as primeiras iniciativas de disseminação do ensino profissionalizante (BARROS, 1956), com o objetivo de aperfeiçoar o conhecimento das artes mecânicas que ainda eram prerrogativa dos mestres de ofícios.

A Sociedade Propagadora das Belas Artes (SPBA) foi criadora e impulsionadora do Liceu de Artes e Ofícios. À frente da SPBA, destacaram-se as posições de Francisco Joaquim Béthencourt da Silva, fundador da Sociedade e principal agente na criação do Liceu do Rio de Janeiro, além de ter estimulado várias iniciativas na área do ensino. O papel desempenhado por Béthencourt da Silva como intelectual não se constitui apenas como aspecto de sua formação letrada. Os elos políticos que estabeleceu à frente dessa instituição ajudaram a consolidar a sua credibilidade e dar a ela um destaque na vida fluminense, a ponto de receber o título de Imperial Liceu de Artes e Oficios, em 1871. Foi este o caso, por exemplo, da aprovação que obteve para o curso comercial, instituído em 1882, no Rio de Janeiro, uma vez que para aprová-lo recorreu à opinião e ajuda da Associação Comercial do Rio de Janeiro (ACRJ), apresentando a ela o projeto inicial proposto para o curso. Apenas mediante a louvada aquiescência de todos os membros da Associação deu-se a aprovação do curso. A isto se seguiu imediatamente a divulgação na imprensa, que atuou de forma conjunta, ressaltando a importância do curso e enfatizando as qualidades já apontadas pela ACRJ para tal iniciativa no Rio de Janeiro.

O lema destacado por Béthencourt da Silva à frente da instituição realça bem os interesses e a amplitude dos ideais formulados pelos intelectuais do período: "Combater a ignorância é defender a liberdade". Esse ideal, no entanto, não marcava apenas os interesses da instituição em torno da divulgação do saber e do conhecimento como elementos fundamentais para a qualificação profissional dos trabalhadores, mas demarcava um campo de atuação política, social e cultural no aspecto da disseminação dos elementos fundamentais para 
"levar o país ao progresso e à civilização". Assim, o conhecimento das artes, visto em sua dimensão civilizadora, encerrava os principais ideais que marcaram o posicionamento do universo intelectual do Brasil no segundo reinado.

\section{Formação de trabalhadores e construção da Nação}

Uma nova perspectiva relacionada à ação dos Estados diante da instrução e educação da sociedade tomava corpo em vários países, na segunda metade do século XIX. Mas essa nova responsabilidade social contava com uma dimensão controladora sobre os costumes, hábitos e a disciplina do trabalho. E a educação foi assumindo esse perfil, que se tornava formadora de uma identidade nacional, ao mesmo tempo que disciplinadora dos "descaminhos" ou tentações da classe trabalhadora. O próprio imperador D. Pedro II, em discurso na cerimônia de inauguração do Liceu de Artes e Ofícios afirmou que "o Liceu não é só educador, é moralizador".

Nesse ponto vale mencionar a análise de Ilmar Rohloff de Mattos sobre o princípio de "derramar a instrução por todas as classes", permanentemente repetido nos discursos de políticos e que apontava para uma determinada ótica sobre a instrução e a educação e seus papéis na sociedade imperial, na medida em que a instrução das classes dirigia-se à difusão das Luzes na expansão de princípios norteadores de valores, na tarefa de romper com os rudimentos de um passado colonial, procurando estabelecer a centralidade do governo do Estado em relação ao governo da Casa. Assim, com base na educação "para todas as classes" buscava-se alavancar os propósitos da difusão da civilidade, no processo de construção do Estado Imperial, aos futuros cidadãos do Império, formando-os para integrarem um corpo nacional (MATTOS, 1994, p. 249-250).

A esse propósito somaram-se os esforços para associar a instrução pública ao caminho de combate à "desordem pública", colocando em prática por diversos meios a combinação entre instrução e trabalho, por meio de projetos que estimularam o ensino de artes mecânicas associados à disseminação dos valores e virtudes morais, consideradas capazes de afastar os mais pobres de crimes, da vagabundagem, etc. Assim, várias políticas e projetos associaram o ensino de artes e ofícios à formação de jovens pobres.

O ponto da discussão entre a aproximação das ideias de instrução e a construção da nação esbarra nos interesses de classe. Nesse sentido, ao se pensar na articulação para que uma entidade representativa dos interesses de boa parcela da classe dominante, como era a Associação Comercial do Rio de 
Janeiro, estivesse tão atenta aos esforços de instrução popular, nos dá algumas pistas sobre o caráter e o sentido que esses projetos assumiram, o público que eles alcançavam, os objetivos a eles articulados e o apoio que receberam de instituições do Império.

Um dos aspectos centrais no desenvolvimento econômico do século XIX, fundamental para a mudança da divisão do trabalho, foi o processo de industrialização e a afirmação de uma ordem econômica e social capitalista. A repercussão das invenções industriais fazia-se em meio à expectativa geral pelas novidades modernas, mas também por uma ansiosa concorrência entre os países mais ricos. Enquanto ocorriam as Exposições Universais da indústria, na segunda metade do XIX, a ideia de progresso se associava cada vez mais ao desenvolvimento do capitalismo industrial e financeiro, para o qual a sociedade deveria se preparar formando seu quadro técnico. No Brasil essa intenção se refletiu nas políticas de fomento à instrução pública e, sobretudo, à acalorada discussão que permeou governo e as instituições no incentivo à formação profissional e à instrução pública, aproximando a expansão do ensino da ideia de sucesso econômico (WERLE, 2008, p. 172)1. A ênfase no ensino de desenho, amplamente discutida nos países que se industrializavam, teve eco no Brasil, influenciando a fundação da Sociedade Propagadora das Belas Artes, exatamente um ano após a segunda Exposição Universal de 1855 (GONDRA; SCHUELER, 2008, p. 73).

Esse incentivo vislumbrava, por um lado, o lento caminhar para o "progresso" e "moralidade" da sociedade por meio do ensino e da instrução. Por outro lado, começava a modelar um corpo técnico de trabalhadores para o comércio e para a indústria, eliminando-se os rudimentos das práticas dos ofícios mecânicos disseminados pelos mestres de ofícios. Um terceiro aspecto importante: preocupava-se em formar os trabalhadores do comércio (caixeiros) para as novas necessidades impostas pelas relações e práticas comerciais. Romper com o arcaísmo colonial significava implementar um ensino que atendesse aos novos projetos políticos e econômicos em pauta, orientados para a formação uníssona de interesses nacionais aliados aos pressupostos de integração entre instrução, economia e progresso social.

Outro ponto importante para reflexão é a relação entre instrução, riqueza e progresso da nação, noções que marcaram o avanço tanto dos estudos quanto da política educacional no século XIX. De acordo com Alves, "multiplicam-se as opiniões na segunda metade de oitocentos que insistem na relação riqueza-

1 A autora afirma: “[...] grande parte das políticas públicas relacionadas à educação decorre da relação, colocada quase como garantia, de que os níveis de educação estão interligados com o sucesso econômico." 
-instrução" (ALVES, 2002, p. 186). Sobretudo nas cidades, onde o crescimento demográfico acelerava-se e as indústrias nasciam, a atuação de diversos setores em prol de uma educação profissionalizante se colocou de forma mais contundente, sob o argumento do enriquecimento nacional e do progresso. Todos esses princípios se confundiam e sintetizavam na educação a premissa de que qualquer caminho para o desenvolvimento industrial futuro do país passaria pelo investimento da instrução.

E nesse ponto a sujeição do processo educativo às transformações do capital fez parte da reestruturação da base de aprendizagem nos países industrializados, na modificação das antigas práticas de trabalho artesanais e manufatureiras, para impulsionarem os vários modelos de expansão industrial. Para atender o desenvolvimento industrial, buscava-se a universalização do ensino, com maior incentivo ao conhecimento técnico e numérico. O processo pedagógico revigorou-se do mesmo incentivo dado à transformação produtiva: inovar e lucrar foram as palavras-chave dessa mudança.

As Exposições Universais também exerceram importante papel de estimularem os debates em torno da formação para o trabalho industrial, especialmente a partir de 1867, quando foram incorporadas as questões assistenciais, inaugurando uma sequência de propostas voltadas para abranger os hábitos de vida, higiene e lazer dos trabalhadores. (KUHLMANN, 1993, p. 160-170). A clara diferenciação estabelecida entre as invenções industriais mostrava-se nitidamente vinculada aos esforços na preparação de uma educação técnica e profissional de caráter nacional, como se viu nos casos da Alemanha e Japão, nos processos de modernização industrial após os anos 1850 .

No texto intitulado "a carreira aberta ao talento" (HOBSBAWN, 1977, p. 211), Hobsbawn recupera o processo de ascensão de classes, a partir do fim da sociedade aristocrática e a valorização crescente do carreirismo individual e de valorização de outras possibilidades de progresso individual das sociedades capitalistas, destacando-se o papel que os negócios, o comércio e a educação representaram. Em todos os casos, a educação pareceu um caminho bem mais difícil de trilhar rumo à ascensão econômico-social do que a estrada dos negócios, porque mesmo nos países onde havia um sistema público de ensino no século XIX, a educação primária era negligenciada. No entanto, o ensino desfrutava de uma certa valorização social, especialmente numa sociedade tradicional, sobretudo porque os estudos "não eram tão antissociais como pareciam ser tão claramente os negócios". Isso abriu caminho para que uma "sede geral de educação" se manifestasse em projetos diversos de educação pública, ainda que a implementação e ampliação do acesso a ela encontrasse uma série de entraves políticos. 
No caso do Brasil Império, os valores crescentes de defesa do talento individual, as premissas de uma competição individualista, conviviam com os valores de uma sociedade aristocrática, em que a nobreza de sangue e uma burocracia nobiliárquica manifestavam-se nas disputas por lugares de prestígio e poder. Esse aparente paradoxo permitiu que se instalasse no Brasil um modelo de ensino que perpetuava as distinções e os privilégios presentes em sua estrutura social, com olhos voltados para o progresso e com os pés mergulhados na escravidão.

Nessa construção ideológica, havia um arcabouço de interesses vitoriosos na arquitetura de uma determinada ideia de nação que vigorou e se consolidou no Brasil. A instrução deveria seguir esses passos: modelar o cidadão de todas as classes, a fim de que fizesse parte de um projeto civilizatório comum. Nesse processo de nacionalização, letras e números tornaram-se protagonistas, vistos como bandeiras do progresso. $\mathrm{O}$ letramento era o caminho necessário para a ampliação das estatísticas de crescimento nacional. O caminho para o progresso passava ainda pela urgente introdução de escolas primárias e pela formação técnica e profissional.

Cada vez mais a educação se apresentava como uma "aposta necessária tanto em termos de funcionalidade econômica, como de qualificação e de afirmação da dignidade" (ALVES, 2001, p. 90). A relação econômica entre instrução, riqueza e investimento industrial aparecia nas rodas intelectuais no Brasil Império. Sobretudo após a Guerra do Paraguai, quando vasta quantia, antes despendida para os gastos da guerra, se voltava para as necessidades internas do Império. A crença sobre o papel redentor da educação para as classes trabalhadoras ganhava corpo e destacava-se no discurso do Imperador, como preocupação do governo e da classe dominante.

Nesse sentido, o Relatório da Associação Comercial do Rio de Janeiro, do ano de 1870, descrevia consecutivas deliberações da entidade após o desfecho da guerra: $1^{\circ}$ ) pela felicitação ao Imperador pelo "brilhante desenlace da guerra, resultado da perseverança imperial"; $2^{\circ}$ ) que se abrisse o corpo de comércio uma subscrição geral para festejar “pomposamente" a volta do Conde D’ $\mathrm{Eu} ; 3^{\circ}$ ) que uma grande parte do produto dessa subscrição fosse aplicada à edificação de escolas para instrução primária. Ao fim do relatório anunciava-se que, em 21 de dezembro, D. Pedro II inauguraria a pedra fundamental de um edifício "destinado a escolas públicas de ambos os sexos da Freguezia de S. Cristóvão" e "o Comércio do Rio de Janeiro terá a glória de haver perpetuado as vitórias brasileiras com um ato de philantropia e caridade". ${ }^{2}$ As breves menções do relatório explicitavam a preocupação da associação em efetivar sua presença junto

2 Dados do Relatório da Associação Comercial do Rio de Janeiro do ano de 1870. Rio de Janeiro: Typographia Perseverança, 1871, p. 6-7. 
ao Imperador, arregimentando em torno dela um aparato comemorativo pela vitória na guerra; e, por outro lado, emoldurava a tela dos interesses nacionais, vinculando-se as preocupações com a instrução e agindo como porta-voz desses interesses. Explicitava-se também um interesse por especial atenção aos estudos relacionados ao comércio, daí as preocupações da Associação Comercial em estimular uma instrução de caráter nacional e também em garantir a instituição das aulas de comércio, que acalentaram os planos de comerciantes desde a chegada da Corte ao Brasil.

\section{Por que estimular o Ensino Comercial?}

É necessário retomarmos um aspecto importante sobre o ensino comercial: desde o século XVIII, em Portugal, as aulas de comércio já atuavam como parte de um processo de instrução e profissionalização das atividades mercantis, que distinguia a atuação de mercadores e negociantes, além de se constituir como restrito caminho à profissionalização de caixeiros e guarda-livros. A chegada da Corte ao Brasil e as novas necessidades de conhecimento sobre o universo comercial ampliaram a demanda por essa profissionalização. Aqui, a Junta de Comércio e as Aulas de Comércio assumiram feições próprias, de acordo com as necessidades que os interesses mercantis assumiam no Brasil, especialmente com a ampliação das relações comerciais com a praça londrina.

Segundo Chaves (2006, p. 4333), eles deveriam aprender o necessário àqueles que quisessem se credenciar como negociantes. Já sabendo ler, escrever e com conhecimentos de cálculo aritmético, a eles era ensinado: história do comércio e manufaturas, escrituração, câmbio, direito mercantil, geografia comercial e náutica e conhecimento de línguas, especialmente o inglês e o francês. Essa profissionalização parece ter conduzido também a uma elitização, conforme defende Chaves, onde os espaços de instrução e profissionalização atuaram também como importantes meios de socialização desses grupos e onde compartilhavam e se organizavam em torno de seus interesses. Distinguia-se assim um setor mercantil com conhecimentos específicos, dos demais setores urbanos que atuavam no comércio, afirmando-se como "perfeitos negociantes". Essa distinção marcou o processo de afirmação dos negociantes em torno de seus interesses, fortalecendo também as instituições de representação deles ao longo do século.

O Decreto $n^{\circ} .456$, de 6/7/1846 foi a primeira regulamentação imperial para a instituição de aulas de comércio e, dez anos depois, em 14/5/1856 o Decreto 
$\mathrm{n}^{\circ} .1 .1763$, criava o Instituto Comercial. Esse plano para o Instituto Comercial parece ter de fato funcionado durante curto espaço de tempo, e a demanda dos comerciantes do Rio de Janeiro tornou-a um símbolo do acalentado interesse pela institucionalização do ensino comercial no Rio de Janeiro. Segundo Bielinsky, o Instituto Comercial começou a funcionar em 1858, no edifício do externato do Colégio Pedro II. No entanto, com mensalidades a serem custeadas pelos caixeiros e o curso funcionando em horário diurno, muitos não podiam arcar com as despesas e estudar durante o dia, levando ao fracasso do curso. Em 1872, Béthencourt da Silva enviava um ofício ao Visconde de Tocantins, então presidente da ACRJ, destacando a importância de se manter e ampliar as aulas de comércio, investindo no ensino comercial:

Ora, o corpo comercial fluminense, embora possua no seu grêmio muitos homens ilustres - primus inter pares - não tem para os vindouros comerciantes uma regular e metódica aprendizagem literária dos úteis conhecimentos de que precisam esses jovens auxiliares de todos os multíplices trabalhos comerciais desta praça, a fim de que mais tarde, devidamente preparados, possam bem substituir os que atualmente constituem o grande foco do movimento mercantil de todo o Império. (ACRJ, 1955).

E sobre a dificuldade de caixeiros frequentarem as aulas do Instituto comercial, deveria ser dada solução exequível, a fim de garantir a introdução do ensino comercial, possibilitando que esses trabalhadores tivessem acesso às aulas. Em resposta a essas dificuldades, ele enviou uma proposta de criação do Curso Comercial pelo Liceu de Artes e Ofícios, propondo a abertura de aulas com esse propósito, em horas que eles já estivessem dispensados do trabalho, possibilitando a frequência deles.

$\mathrm{O}$ insucesso e as tentativas posteriores de reerguer o Instituto Comercial tornaram o sonho da instituição uma meta a ser defendida pela ACRJ nos anos seguintes. Entretanto, foi muito bem recebida pela Associação a proposta feita por Béthencourt da Silva: abrigar no Liceu um curso comercial com aulas noturnas, mais acessíveis aos trabalhadores do comércio, que exerciam suas atividades durante o dia. Ainda assim, outras tentativas de recriação do Instituto Comercial foram empreendidas. Em 1882, os diretores discutiram sobre um ofício do Ministro do Império, com um exemplar do projeto de criação de uma Universidade, pedindo o parecer da ACRJ sobre a parte relativa à organização do Instituto Comercial. Essas propostas mostravam também uma tentativa de afirmação política da ACRJ junto ao governo, ainda que sua pressão não tenha 
gerado resultado na concretização de montagem de uma instituição destinada unicamente ao ensino comercial.

Mas qual era a argumentação utilizada pela associação na defesa de um instituto que abrigasse o curso comercial e por que ele se fazia tão importante na discussão sobre instrução pública no Império? Por que um curso comercial tornava-se uma bandeira da associação? Vejamos: Em 1904, o Boletim da Associação Comercial do Rio de Janeiro definia em algumas linhas os objetivos de se instituir aulas de comércio, refletindo sobre a pouca valorização dada ao referido ensino:

Para muitos ainda, para quem o comércio não figura entre as profissões superiores, não exigindo, portanto, mais do que os conhecimentos escolares, uma prática fácil de adquirir, o falar-se em estudos especiais e superiores do comércio, parece, senão uma heresia, uma pura fantasia sem vantagem na realidade, vendo-se, em geral, prosperam, a classe, os menos instruídos e os mais atrevidos, embora sem conhecimentos nenhuns. (ACRJ, 1904, p. 4).

Para tanto se defendia um aprendizado que pudesse auxiliar em funções básicas do comércio, tais como: tirar fatura, redigir carta, saber atender em balcão. Era a ênfase num aprendizado direcionado para as necessidades das atividades comerciais e uma espécie de "conhecimentos gerais" sobre as demais áreas de conhecimento. A ACRJ defendia que essas funções, aparentemente simples, demandavam uma formação aprofundada em conhecimentos relacionados a diversos "campos da ciência", sendo necessário ainda o conhecimento que se estendesse a outros países, e ainda o entendimento da "geografia comercial":

É preciso sublinhar também que o alargamento das relações comerciais internacionais dos oitocentos começou a criar um conjunto de novas demandas de especialização para o comércio. Algumas mudanças começaram a gerar impactos importantes nas atividades comerciais, tal como a padronização dos pesos e medidas. Essa medida era considerada fundamental para o aprimoramento e ampliação das possibilidades de transações comerciais entre diferentes regiões e países, além de colocar o país na rota das transformações científicas do período. Entretanto, significava também ter um corpo de trabalhadores preparados para essa realidade, formados na prática do comércio para atender a nova normatização jurídica e capacitados a entenderem sobre o novo padrão de equivalência de medidas.

As revoltas conhecidas como Quebra-Quilos mostraram, entre os anos 1870 e 80, a indignação de parcela da sociedade com a imposição de um sistema 
de pesos e medidas, cuja adoção repentina representou um prejuízo para muitos pequenos comerciantes e trabalhadores ligados ao comércio. A Lei $\mathrm{n}^{\circ} 1.157$, aprovada em junho de 1862, determinava a substituição do sistema de pesos e medidas utilizado até aquele período pelo sistema métrico francês e estabelecia o prazo de 10 anos para o aprendizado do novo método e a introdução definitiva dele (LIMA, 2012, p. 4).

A proposta de adoção do sistema métrico francês no Brasil foi feita pela primeira vez em 1830, no projeto apresentado por Candido Batista de Oliveira. Em 1834, uma comissão criada pelo ministério da fazenda assim definia a necessidade de reformar o sistema de pesos e medidas no país (MOREIRA; MASSARINI, 1997, p. 15). Apenas nos anos 1860 o sistema métrico decimal foi implementado, comprometendo-se o governo a trazer da França os necessários padrões para o sistema, introduzir na instrução primária o ensino sobre a nova padronização, organizar tabelas comparativas que facilitassem a conversão de um sistema ao outro. Entretanto, o governo não cumpriu o que fora estabelecido e o novo padrão acabou representando um problema para as atividades econômicas.

O comércio encontrou muitas dificuldades para colocar em prática a lei, visto a desinformação a respeito do seu emprego, das equivalências e cálculos necessários para a aplicação do novo sistema. Tanto que, em 1872, a ACRJ criou uma comissão para discutir o novo padrão. A Lei, aprovada dez anos antes, previa que dentro desse período cessaria inteiramente o antigo sistema de pesos e medidas e que as escolas de instrução primária compreenderiam no ensino da aritmética a explicação do sistema métrico comparado com o sistema de pesos e medidas ora adotado: o sistema métrico francês. Entretanto, mesmo a ACRJ só teve acesso aos manuais para ensino sobre o novo sistema métrico em 1872, mostrando a desorganização do governo na imposição e difusão do novo sistema. E consta que o governo não tomou mesmo providências para que fosse substituído o antigo padrão, apenas cuidando expressamente da severa punição aos que não cumprissem a lei. Souto Maior descreve uma crítica feita pelo engenheiro Guilherme Schüch de Capanema (futuro Barão de Capanema e conhecido defensor da implantação do sistema métrico no Brasil), no jornal $A$ Reforma, em 1873, afirmando que os cidadãos eram obrigados a mudarem seus hábitos subitamente, sem que o governo expedisse o regulamento e fizesse a distribuição dos padrões, sem dizer ao consumidor onde encontrar tais medidas e pesos (MAIOR, 1978, p. 22).

Outro aspecto que não podemos perder de vista no incentivo dado à implementação do curso comercial também pode estar relacionado à necessidade de haver maior controle sobre a atuação dos trabalhadores do comércio, conhecidos como caixeiros. Sabemos que a partir dos anos 1880 houve uma série de ações dos caixeiros em defesa do estabelecimento de número de horas 
para o trabalho e o fechamento das portas nos domingos e feriados (MARTINHO; GORENSTEIN, 1993, p. 40). Essa demanda significou, no caso do Rio de Janeiro, uma conflituosa sequência de ações das sociedades e associações caixeirais, que culminaram na aprovação e publicação da Lei em 24 de junho de 1911, estabelecendo as 12 horas máximas de trabalho por dia e os dias da semana em que os estabelecimentos ficariam fechados integral ou parcialmente (POPINIGIS, 1999, p. 111). Mas esses conflitos se estenderam durante pelo menos três décadas em várias províncias. Em 1880, já havia sido aprovada pela Câmara Municipal do Rio de Janeiro postura que determinava o fechamento das portas aos domingos e dias santos para vários trabalhadores do comércio, mas uma reação dos patrões em defesa da "liberdade de comércio" acabou provocando a sua revogação. E os anos 1880 e 90 se caracterizaram pela crescente força do movimento pelo fechamento das portas do comércio na cidade. $\mathrm{Na}$ província do Rio Grande do Sul, as tensões entre patrões e empregados significou uma aproximação dos caixeiros com os ideais do movimento operário, se identificando com suas reivindicações (DUARTE, 2000, p. 159). Os Clubes Caixeirais surgiram no Rio Grande do Sul nos anos 1880 e até os anos 90 foram fundados doze clubes e cerca de $21 \%$ das entidades mutuais existentes eram de representação de caixeiros.

Esses dados mostram a força da atuação política dos trabalhadores do comércio. Se vários desses caixeiros conseguiram ascender socialmente ao longo da vida de trabalho e tornaram-se comerciantes, outros tantos continuavam partícipes de uma realidade onde muitas vezes se aproximavam dos mais baixos estratos da sociedade (MARTINHO; GORENSTEIN, 1993, 45). No entanto, sua condição diferenciada quanto às origens que os tornavam caixeiros - visto que precisavam ter conhecimento dos números e letras - concorriam para que houvesse uma demanda por uma formação profissional mais qualificada e direcionada para o trabalho no comércio, favorecendo as atividades mercantis.

Por outro lado, as prerrogativas das quais usufruíram os caixeiros no desempenho do trabalho no comércio - que envolvia a possibilidade de participar da vida política como eleitores e estar dispensados das obrigatoriedades militares -, tinham a marca de uma certa distinção social em relação aos demais trabalhadores. Isso teve especial significado numa cidade como o Rio de Janeiro, onde essas distinções na esfera do trabalho repercutiram em conflitos diversos ao longo dos oitocentos. Martinho mostrou, em estudo sobre os caixeiros do Rio de Janeiro, como muitos movimentos de caráter antilusitano, após a Independência, tiveram relação com a monopolização de empregos no comércio por esses caixeiros que vinham de Portugal, uma vez que eles ainda desfrutavam de uma série de privilégios, num meio urbano marcado pela presença de uma população livre pobre e escrava. 
Em estudo sobre a formação da identidade nacional ao longo do primeiro reinado, Ribeiro mostrou como a formação dessa identidade do "ser brasileiro", que se construiu em oposição ao "ser português", esteve fortemente vinculada aos aspectos políticos e marcada pela convivência entre os trabalhadores portugueses e os "brasileiros" por fatias do mercado de trabalho, uma vez que os portugueses tinham garantidos os melhores empregos, possibilidades de ascensão e certas prerrogativas que os favoreciam em relação aos demais trabalhadores (RIBEIRO, 2002). Ainda que o processo de afirmação de uma identidade nacional tenha modificado paulatinamente as características dos conflitos entre brasileiros e portugueses ao longo dos oitocentos, eles estiveram presentes até as primeiras décadas do século XX, marcados pela luta pela sobrevivência e melhores condições de trabalho e de vida. A mesma autora, em estudo anterior, afirmou que entre 1884 e 1930 a entrada de portugueses no Brasil foi quatro vezes maior que entre 1820 e 1883 (RIBEIRO, 1990, p. 8). Disputando o trabalho nas freguesias urbanas, esses estrangeiros continuavam sendo encarados como inimigos e vistos como monopolizadores de algumas atividades, especialmente ligadas ao comércio.

Esses elementos nos mostram que as reivindicações dos setores ligados às atividades comerciais ganharam corpo e cresceram na segunda metade do século XIX, refletindo a ampliação de funções destinadas ao comércio naquele momento e ao aumento das demandas relacionadas aos caixeiros. A defesa de institucionalização das aulas de comércio representou um ideal acalentado pela Associação Comercial, embora o maior aliado na introdução e difusão do ensino comercial tenha sido o Liceu de Artes e Ofícios, a partir de 1882.

\section{Conclusão}

Retomando os ideais daqueles negociantes que contribuíram financeiramente para o incentivo à instrução pública, em 1815, mencionado no início deste artigo, verifica-se a continuidade dessas iniciativas ao longo do século. Um ato, sem dúvida, simbólico, destilava as intenções consideradas filantrópicas; por outro, uma ação que se relacionava ao processo de afirmação política dos comerciantes da Praça, articulados à corte joanina. Essas iniciativas de apoio à instrução popular se deram de forma difusa e pouco articulada ao longo das décadas seguintes. A descentralização da gestão do ensino escolar acabou produzindo outro cenário de dificuldades para essa integração entre projetos, ideais e práticas. Destacaram-se na Corte os modernos prédios escolares e de 
ensino profissional, construídos ou incentivados pela Associação Comercial do Rio de Janeiro, que continuou se referindo com frequência à necessidade de incentivo à instrução.

Contudo, o processo de instrução e profissionalização mercantil que analisamos neste artigo mostrou uma realidade diferenciada nas últimas décadas do século XIX. Naquele momento, o ensino comercial tinha claro direcionamento aos trabalhadores do comércio, aqueles que no dia a dia precisavam de conhecimentos específicos para lidar com as transformações relacionadas às várias facetas da atividade mercantil. A ampliação das trocas internacionais também obrigava os países a se inserirem em um novo e amplo conjunto de preocupações, ancoradas em algum conhecimento sobre os aspectos jurídicos relacionados às legislações sobre o comércio, contabilidade, padronização de pesos e medidas, etc. Por outro lado, o processo de institucionalização da instrução pública provocou também a busca por instituições que cuidassem da profissionalização e dos aspectos morais relacionados a essa formação. E foi nesse ponto que o Liceu de Artes e Ofícios perpetuou a memória do ensino comercial no Império com a instituição do Curso Comercial.

\section{REFERÊNCIAS}

ALVES, L. A. M. O Ensino na segunda metade do século XIX. Revista da Faculdade de Letras, História, Porto, III. Série, v. 2, p. 53-92, 2001.

ALVES, L. A. M. A Escola Faria Guimarães no contexto do Ensino Industrial (18851910). Revista da Faculdade de Letras, História, Porto, III Série, v. 3, p. 186, 2002.

BARROS, P. O Liceu de Artes e Ofícios no Rio de Janeiro e seu fundador. Rio de Janeiro: LAO, 1956.

BIELINSKI, A. C. Educação profissional no século XIX: curso comercial do Liceu de Artes e Ofícios: um estudo de caso. Disponível em: $<$ http://www.senac.br/informativo/ BTS/263/boltec263e.htm>. Acesso em: 12 jun. 2007. p. 1-13.

CHAVES, C. M. Métodos e práticas do ensino mercantil profissionalizante no Império Luso-Brasileiro (1788-1822). In: CONGRESSO LUSO-BRASILEIRO DE HISTÓRIA DA EDUCAÇÃO. Percursos e Desafios da Pesquisa e do Ensino de História da Educação, 6., 2006. Anais... Uberlândia: UFU, 2006. Disponível em: <http://www2.faced.ufu. br/colubhe06/anais/arquivos/392ClaudiaMariaChaves.pdf $>$. Acesso em: 12 jun. 2007.

CUNHA, L. A. O ensino de ofícios nos primórdios da industrialização. São Paulo: Editora Unesp; Brasília, DF: Flacso, 2000. 
DUARTE, P. C. B. Fundação e os objetivos dos Clubes Caixeirais no Rio Grande do Sul. 1879 a 1890. História em Revista, Pelotas: UFPEL, v. 6, p.159-167, 2000.

FREITAS, J. J. R. de. Novas páginas avulsas. Porto: Fundação Eng. Antonio de Almeida, 1996. p. 142-143.

GONDRA, J. G.; SCHUELER, A. Educação, poder e sociedade no império brasileiro. São Paulo: Cortez, 2008.

HOBSBAWM, E. A Era das Revoluções, 1789-1848. 10. ed. Rio de Janeiro: Paz e Terra, 1977.

KUHLMANN JÚNIOR, M. As Exposições Universais e a utopia do controle social. In: XVII SIMPÓSIO NACIONAL DE HISTÓRIA, 17., São Paulo, 1993. Anais... São Paulo, julho 1993. p. 169-170.

LIMA, V. de O. Revoltas dos Quebra-Quilos: contra a imposição do sistema métrico-decimal, XV In: ENCONTRO REGIONAL DE HISTÓRIA, 15., 2012. Anais... 2012. Disponível em: $<$ http://www.encontro2012.rj.anpuh.org/resources/anais/15/1338335004 ARQUIVO_ANPUHRevoltas-Textofinal.pdf>. Acesso em: 13 fev. 2017.

MAC CORD, M. A década de 1870 e as políticas de 'instrução popular': a complexa arquitetura do Liceu de Artes e Ofícios do Recife. Revista Uniabeu, Belford Roxo, v. 1, n. 1, set.-dez. 2010.

MAC CORD, M. Redes de sociabilidade e política: mestres de obras e política no Recife oitocentista. Revista Mundos do Trabalho, v. 2, n. 4, p. 109-125, ago.-dez. 2010.

MAIOR, A. S. Quebra-Quilos: lutas sociais no outono do Império. São Paulo: Editora Nacional, 1978. (Brasiliana, v. 366).

MARTINHO, L.; GORENSTEIN, R. Negociantes e Caixeiros na Sociedade da Independência. Rio de Janeiro: Secretaria Municipal de Cultura, 1993. Biblioteca Carioca, v. 4.

MATTOS, I. R. de. O Tempo Saquarema: a formação do Estado Imperial. 3. ed. Rio de Janeiro: Access, 1994.

MOREIRA, I. de C.; MASSARINI, L. Cândido Batista de Oliveira e seu papel na implantação do sistema métrico decimal no Brasil. Revista da Sociedade Brasileira de História da Ciência, n. 18, p. 3-16, 1997.

MURASSE, C. M. A Educação para a Ordem e o Progresso do Brasil: o Liceu de Artes e Ofícios do Rio de Janeiro (1856-1888). Tese (Doutorado em Educação) - Programa de Pós-Graduação em Educação, Unicamp, Campinas, 2001.

POPINIGIS, F. As Sociedades Caixeirais e o 'fechamento das portas' no Rio de Janeiro (1850-1912). Cadernos AEL, v. 6, n. 10/11, p. 111-146, 1999.

RIBEIRO, G. S. Mata Galegos: os portugueses e os conflitos de trabalho na República Velha. São Paulo: Brasiliense, 1990. 
RIBEIRO, G. S. A liberdade em construção: identidade nacional e conflitos antilusitanos no primeiro reinado. Rio de Janeiro: Relume Dumará/Faperj, 2002.

SQUEFF, L. O Brasil nas Letras de um Pintor: Manuel de Araújo Porto Alegre (18061879). Campinas, SP: Editora da Unicamp, 2004.

VILLELA, H. A trajetória de um professor negro no Brasil escravocrata. In: OLIVEIRA, I. (Org.). Relações raciais no contexto social, na educação e na saúde: Brasil, Cuba, Colômbia e África do Sul. Rio de Janeiro: Quartet, 2012.

WERLE, F. C. Políticas de instrução pública no século XIX como eco de experiências internacionais, Educação, v. 31, maio-agosto, 2008.

\section{Fontes primárias e periódicos}

ACTA da sessão da Diretoria da ACRJ, do dia 2 de dezembro de 1882.

ACRJ. O Ensino Comercial. Boletim número 27, 30/08/1904.

BOLETIM da Associação Comercial do Rio de Janeiro, edição n. 1, 1 de março de 1904.

MAGALHÃES, F. de. Discurso proferido no Liceu Literário Português. Rio de Janeiro, 06/1884. Coleção Decimal. Biblioteca Nacional, I-48,31,33. Mss370.6 M. R 205/1906.

O PAIZ. Lyceu de Artes e Officios. Rio de Janeiro, 24/11/1885.

RELATÓRIO da Associação Comercial do Rio de Janeiro do ano de 1870. Rio de Janeiro: Typographia Perseverança, 1871, p. 6-7.

REVISTA da ACRJ, Ano XVIII, n. 804 (49), 10/09/1955.

Texto recebido em 03 de março de 2017 Texto aprovado em 31 de outubro de 2017. 
